\title{
Effect of Wheat Cultivar on the Concentration of Fusarium Mycotoxins in Wheat Stems
}

Kaitlyn M. Bissonnette, Frederic L. Kolb, and Keith A. Ames, Department of Crop Sciences, University of Illinois, Urbana 61801; and Carl

A. Bradley, ${ }^{\dagger}$ Department of Plant Pathology, University of Kentucky Research and Education Center, Princeton 42445

\begin{abstract}
Effective control of Fusarium-mycotoxin accumulation in grain affected by Fusarium head blight (FHB) (caused by Fusarium graminearum) begins with selecting moderately resistant wheat cultivars; however, little is known about how this resistance affects mycotoxin levels in the stem. A study was conducted from 2011 to 2014 in a mist-irrigated FHB nursery in Urbana, IL to determine whether the FHB resistance class of a cultivar (very susceptible, susceptible, moderately susceptible, and moderately resistant) affects the concentration of Fusarium mycotoxins in the stem. FHB incidence, FHB severity, and Fusarium-damaged kernel ratings were collected and used to calculate FHB index; incidence, severity, and kernel damage (ISK) index; and deoxynivalenol (DON), incidence, severity, and kernel damage (DISK) index. Grain was assayed for levels of DON, and the bottom $25 \mathrm{~cm}$ of plant stems was collected from each

plot and assayed for DON, 3-acetyl-deoxynivalenol (3ADON), and 15acetyl-deoxynivalenol (15ADON). Significant differences in DON concentration in the grain were detected among cultivars $(P=0.0001)$ and for the concentration of all DON $(P=0.003), 3 \mathrm{ADON}(P=0.03)$, and 15ADON $(P<0.0001)$ in the stem. Significant differences among resistance classes were observed for FHB index value $(P<0.0001)$, ISK index $(P=0.006)$, and DISK index $(P=0.004)$. In all years of this study, the concentration of DON in the grain and the concentrations of all mycotoxins in the stem were consistently lower in the moderately resistant cultivars. All three indices were poor indicators of mycotoxin concentrations in the stem. Overall, the selection of a moderately resistant cultivar provides effective control of DON accumulation in the grain and mycotoxin accumulation in the stem.
\end{abstract}

Fusarium head blight (FHB), caused by Fusarium graminearum, is a disease of small-grain cereal crops that is responsible for millions of dollars in annual crop losses worldwide resulting from the presence of mycotoxins and the development of shriveled, Fusarium-damaged kernels (FDK) (Nganje et al. 2004; Shaner 2003). Deoxynivalenol (DON) and its acetylated derivatives, 3-acetyl-deoxynivalenol $(3 \mathrm{ADON})$ and 15-acetyl-deoxynivalenol (15ADON), are the most common mycotoxins associated with FHB. DON is currently regulated in grain in the United States by the Food and Drug Administration at 1 $\mathrm{ppm}$ in finished grain products for human consumption, $5 \mathrm{ppm}$ for swine feed, and $10 \mathrm{ppm}$ for nonruminant feed (USDA FDA 2010). Control of FHB and related mycotoxins in grain production relies primarily on the use of resistant cultivars (Blandino et al. 2012; Paul et al. 2008, 2010) and the application of demethylation inhibitor fungicides.

Several categories of FHB resistance have been described in wheat (Triticum aestivum), including type I resistance (resistance to initial infection) and type II resistance (resistance to the spread of the fungus within the host) (Schroeder and Christensen 1963). Type I resistance is assessed by evaluating the percentage of FHB-symptomatic heads (incidence) and can be difficult to assess at low levels of infection. Type II resistance is assessed by evaluating severity (which is a way to quantify the spread of infection through the spike). Research has largely focused on the advancement of FHB-resistant wheat breeding lines with type II resistance due to their ability to not only reduce the spread of infection but also reduce mycotoxin

Current address of K. M. Bissonnette: Division of Plant Sciences, University of Missouri, Columbia 65211.

${ }^{\dagger}$ Corresponding author: C. A. Bradley; E-mail: carl.bradley@uky.edu

Funding: This material is based upon work supported by the United States Department of Agriculture-Agricultural Research Service under Agreement Number 59-0206-9-076. This is a cooperative project with the U.S. Wheat \& Barley Scab Initiative.

Accepted for publication 31 May 2018.

C) 2018 The American Phytopathological Society concentrations in the grain (Buerstmayr and Buerstmayr 2015; Buerstmayr et al. 2002, 2009; Jiang et al. 2007; Prat et al. 2014).

In breeding for FHB resistance in wheat cultivars, indices are commonly used to assess the performance of cultivars against Fusarium infection in the field and in the greenhouse. These indices use combinations of visual assessment characteristics such as disease incidence, disease severity, FDK, and DON concentration in the grain. The FHB index has historically been the most commonly used index to assess resistance to FHB, and is based on both FHB incidence and severity levels (Snijders 1990). However, FHB index may not account for several key factors in estimating FHB in wheat, especially how type II resistance traits that limit the spread of the fungus in the host affect mycotoxin concentrations.

Two other indices have been used to assess FHB in FHB field genotype-screening nurseries: the incidence, severity, and kernel damage (ISK) index (Kolb and Boze 2003) and the DON, incidence, severity, and kernel damage (DISK) index (Gilbert and Woods 2006). Both of these indices are based on FHB incidence and severity levels but also include FDK or grain DON concentration in their overall calculations. The ISK index includes FDK ratings due to their importance in the end use of the grain and their relationship to mycotoxin concentration (Miller et al. 1985). The DISK index was modified from the ISK index and includes both FDK and grain DON concentration to better assess the impacts of type II resistance traits that result in reduced DON accumulation. These indices all play important roles in the development and advancement of cultivars with resistance to $F$. graminearum infection and for reducing DON concentration in the grain. The development of cultivars exhibiting resistance to FHB and mycotoxin accumulation is pivotal for the management of this disease and the reduction of mycotoxins in grain production.

Mycotoxins also have been reported to accumulate in stems of wheat plants infected with Fusarium spp. (Häggblom and Nordkvist 2015; Nordkvist and Häggblom 2014; Rohweder et al. 2011, 2013). Often, wheat straw is used for bedding in livestock production. Swine, in particular, are known to consume their bedding, which can comprise up to $13 \%$ of their diet (van Barneveld et al. 2005), which can increase their risk of exposure to Fusarium mycotoxins (Nielsen and Ingvartsen 2000; Veum et al. 2009). Feed refusal and vomiting are the primary symptoms that swine exhibit when exposed to the Fusarium mycotoxins DON, 3ADON, 15ADON, nivalenol, 
and zearalenone, and often result in decreased weight gain and, in extreme cases, female reproductive problems (Marasas et al. 1979; Mirocha et al. 1967, 1976; Vesonder and Hesseltine 1981). Very little is known about how these mycotoxins are accumulating, or how cultivar resistance to FHB affects this accumulation.

The main objectives of this study were to determine whether (i) the level of FHB resistance of a cultivar is associated with the concentration of Fusarium mycotoxins in the stem, (ii) the concentration of Fusarium mycotoxins in the stem are significantly correlated to the levels of mycotoxins accumulating in the grain, and (iii) select indices used for the advancement of FHB resistance in wheat cultivars are effective indicators of Fusarium mycotoxin concentrations in the stem.

\section{Materials and Methods}

Field trials were conducted at the University of Illinois Crop Sciences Research and Education Center in Urbana from 2011 through 2014. Each year, 16 to 20 soft red winter wheat cultivars with different FHB reaction (VS $=$ very susceptible, $\mathrm{S}=$ susceptible, $\mathrm{MS}=$ moderately susceptible and, MR = moderately resistant) were planted on 29 September 2010, 23 October 2011, 9 October 2012, and 10 October 2013 and were spaced $0.3 \mathrm{~m}$ apart in 1.2-m-long single-row plots

Table 1. Wheat cultivars and their respective resistance classes in each year of the study

\begin{tabular}{|c|c|}
\hline Resistance class, cultivar ${ }^{\mathbf{a}}$ & Year \\
\hline \multicolumn{2}{|l|}{$\overline{\mathrm{MR}}$} \\
\hline IL07-4415 & 2013,2014 \\
\hline IL02-18228 & 2013,2014 \\
\hline Excel 168 & 2011 \\
\hline Excel 180 & 2011 \\
\hline \multicolumn{2}{|l|}{ MS } \\
\hline Barbie9 & 2014 \\
\hline Diener512W & 2013,2014 \\
\hline Ernie & 2014 \\
\hline Excel 166 & 2011 \\
\hline Excel 209 & 2011 \\
\hline Excel 442 & 2011 \\
\hline KSC409W & 2013,2014 \\
\hline KSC410W & 2011 \\
\hline KSC412W & 2013 \\
\hline Oakes & 2011 \\
\hline Pioneer 25R46 & 2014 \\
\hline Pro220 & 2011 \\
\hline Skysail & 2014 \\
\hline SY1526 & 2011,2013 \\
\hline \multicolumn{2}{|l|}{ S } \\
\hline Beck135 & 2011,2013 \\
\hline Exp101 & 2013 \\
\hline Hunker & 2014 \\
\hline Pioneer 25R34 & 2011, 2013, 2014 \\
\hline Pioneer 25R39 & 2011,2013 \\
\hline Pioneer 25R40 & $2011,2013,2014$ \\
\hline Pioneer 25R46 & 2013 \\
\hline Pioneer 25R62 & 2011,2013 \\
\hline Pioneer 25R77 & 2013,2014 \\
\hline Pro288 & 2013 \\
\hline Quest & 2011,2013 \\
\hline Sienna & 2011,2013 \\
\hline \multicolumn{2}{|l|}{ VS } \\
\hline DWExp102 & 2011 \\
\hline FS602 & 2014 \\
\hline Pioneer 25R47 & 2011,2013 \\
\hline $\mathrm{PRO} 240$ & 2013,2014 \\
\hline SY483 & 2014 \\
\hline W1104 & 2011, 2013, 2014 \\
\hline W1566 & 2011 \\
\hline
\end{tabular}

${ }^{a}$ Resistance classes were moderately resistant (MR), moderately susceptible (MS), susceptible (S), and very susceptible (VS).
(Table 1). Plots were arranged in a randomized complete block design with three replications. $F$. graminearum-infested corn kernels were prepared by adding pure isolates of $F$. graminearum (recovered from Fusarium-infected wheat and grown on half-strength potato dextrose agar) to sterilized (autoclaved) corn kernels which were then allowed to grow at room temperature and mixed regularly to ensure uniform colonization. Kernels were spread throughout the plots prior to heading at an approximate rate of $225 \mathrm{~kg} / \mathrm{ha}$. Mist irrigation was applied three times per day for a 1-h duration each time, beginning 2 weeks prior to anthesis and continuing until 2 weeks after anthesis. Plots were visually rated for FHB incidence (the percentage of heads with FHB symptoms in the whole plot) and FHB severity (based on 10 randomly selected heads per plot using the severity rating scale reported by Stack and McMullen [2011]). Due to drought conditions in 2012, low FHB incidence and severity were observed in all cultivars in spite of mist irrigation being utilized. For this reason, data collected in 2012 were not included in the statistical analysis. The bottom portion of stem was collected from each single-row plot by hand at harvest by trimming the stem to approximately $25 \mathrm{~cm}$ tall and cutting the stem at the base of each plant. Stems were collected from a $0.2-\mathrm{m}$ section of each plot. Stem samples were dried in a forced-air drier at $32^{\circ} \mathrm{C}$, ground using a Microfine grinder (IKA Works, Inc., Wilmington, NC) and portioned into 4-g samples. Grain samples from each plot were visually evaluated for Fusarium damage and FDK were estimated using a 0-to-100\% rating scale (Engle et al. 2000).

Mycotoxin analysis. All mycotoxin testing was conducted at the University of Minnesota mycotoxin testing laboratory in St. Paul. The concentrations of DON, 3ADON, 15ADON, nivalenol, and zearalenone were measured in stem samples using methods modified from Tanaka et al. (2006) and reported in parts per million. Mycotoxins were extracted from each 4-g ground stem sample with $16 \mathrm{ml}$ of acetonitrile-water (84:16 [vol/vol]). The sample was then placed on a shaker for $1 \mathrm{~h}$, after which $4 \mathrm{ml}$ of extract was passed through a column packed with $\mathrm{C} 18$ and aluminum oxide (1:3 [wt/wt]). The filtrate $(1 \mathrm{ml})$ was evaporated to dryness under nitrogen at room temperature and derivatized by a silylating reagent (TMSI/TMCS, 100:1) for gas chromatography mass spectrometry analyses (Shimadzu GCMS-QP2010; Shimadzu Corporation, Kyoto, Japan). Only the concentration of DON was measured in the grain samples using the methods described above.

Indices. Three indices were used to measure each cultivar's performance in the FHB nursery and were calculated using values reported from visual characteristics and DON concentration in the grain. The indices calculated were: FHB index, calculated using the equation Index $=($ Incidence $\times$ Severity $) / 100($ Snijders 1990); ISK index, calculated as reported by Kolb and Boze (2003) by the equation ISK $=(0.3) \times$ Incidence $+(0.3) \times$ Severity $+(0.4) \times$ FDK; and DISK index, calculated using the equation DISK $=(0.2) \times$ Incidence $+(0.2) \times$ Severity $+(0.3) \times \mathrm{FDK}+(0.3) \times$ grain DON and developed by Gilbert and Woods (2006).

Data analysis. All data analyses were conducted using SAS statistical software (version 9.4; SAS Institute Inc., Cary, NC) using the mixed-model procedure (PROC MIXED). Class of resistance (VS, $\mathrm{S}, \mathrm{MS}$, and MR) was considered to be a fixed effect and year and replication were considered random effects. Cultivars varied year to year but all four resistance classes were represented each year (Table 1). Mycotoxin concentrations were log-transformed $(\log \mathrm{DON}=\log$ $[\mathrm{DON}+1], \log 3 \mathrm{ADON}=\log [3 \mathrm{ADON}+1]$, and $\log 15 \mathrm{ADON}=$ $\log [15 \mathrm{ADON}+1])$ in order to homogenize variances and to account for missing data. Random effects of the model were estimated using best linear unbiased predictors, and Spearman correlation analyses were performed using the Spearman correlation procedure (PROC CORR SPEARMAN) to account for missing data points. Significant differences among cultivars were determined using a Tukey's W procedure with $\alpha=0.05$.

\section{Results}

Mycotoxin concentration and index ratings were significantly affected by resistance class in this study. For all models, the two-way 
interaction of year-resistance class was either not significant or not estimable due to it not contributing to the variance of the model (Table 2). Year was not significant for levels of DON in the grain, 3 -ADON in the stem, ISK, and DISK (Table 2). However, year was significant for DON $(P=0.05)$ and 15-ADON $(P=0.001)$ in the stem and for FHB index $(P=0.0002)$.

Significantly $(P \leq 0.05)$ lower concentrations of DON and $15 \mathrm{ADON}$ were observed in the stem of the MR cultivars compared with all other resistance classes (Fig. 1). DON concentration in the stem averaged $8.6 \mathrm{ppm}$ in the MR cultivars, almost one-third the DON concentrations observed in the stem of the $S(22.7 \mathrm{ppm})$ and VS (21.2 ppm) cultivars (Fig. 1). A similar lower 15ADON concentration in the MR cultivars (2.5 ppm) was observed when compared with the 15ADON concentration in the stem of the $S(6.1 \mathrm{ppm})$ and VS (5.4 ppm) cultivars. The concentration of DON was not significantly different between the VS and the $\mathrm{S}$ cultivars but the concentrations of DON in these classes were significantly $(P \leq 0.05)$ different from the concentration of DON in the MR cultivars. Significant differences were not observed in the stem between the VS and S cultivars and between the $S$ and MS cultivars for the concentration of $15 \mathrm{ADON}$, or across all resistance classes for the concentration of 3ADON. Unlike the stem, DON concentration in the grain was significantly $(P \leq 0.05)$ different among all resistance classes.

Spearman correlation analyses revealed significant, positive correlations between the DON concentrations detected in the grain and the concentration of DON $(P<0.0001, R=0.33), 3 \mathrm{ADON}(P<0.0001$, $R=0.30)$, and 15ADON $(P=0.04, R=0.16)$ detected in the stem across all resistance classes (Table 3 ). When grouped by resistance class, DON concentration in the grain was not significantly correlated to the mycotoxin concentrations in the stem for any of the four resistance classes. When all resistance classes were combined, a significant, positive correlation was observed between DON and $3 \mathrm{ADON}(P<0.0001)$ concentrations in the stem and DON and 15ADON $(P<0.0001)$ concentrations in the stem, with Spearman correlation coefficients of 0.71 and 0.81 , respectively (Table 4$)$. Significant, positive correlations were also observed for DON and $3 \mathrm{ADON}$ concentrations in the stem and DON and 15ADON concentrations in the stem for the VS cultivars $(P<0.0001, R=0.65$ and $P<$ $0.0001, R=0.82$, respectively), the $\mathrm{S}$ cultivars $(P<0.0001, R=0.49$ and $P<0.0001, R=0.83$, respectively), the MS cultivars $(P<0.0001$, $R=0.73$ and $P<0.0001, R=0.75$, respectively), and the MR cultivars $(P=0.006, R=0.62$ and $P<0.0001, R=0.89$, respectively).

Resistance classes also differed significantly for index values (Table 2). The values of all indices were lower in the MR cultivars than they were in all other resistance classes (Fig. 2). Significant differences $(P \leq 0.05)$ in FHB index values were observed among all resistance classes. These differences may not be true indicators of the differences among the classes due to differing numbers of entries in various resistance classes and due to a large amount of variability unaccounted for by the model, as is indicated by the large error term (Table 2). Differences in ISK and DISK values were observed among resistance classes, with significantly lower index values observed in the MR cultivars compared with all other resistance classes (Fig. 2). However, the differences between the VS and S cultivars and between the S and MS cultivars were not significant for either ISK or DISK.

Spearman correlation analyses revealed significant, positive correlations among each index and all three mycotoxins observed in the stem. Over all resistance classes, there was a significant, positive correlation between FHB index and DON concentration $(P<0.0001$, $R=0.37)$, FHB index and 3ADON concentration $(P=0.002, R=0.24)$, and FHB index and 15-ADON concentration $(P<0.0001, R=0.33)$ in the stem (Table 5). Significant, positive correlations were also observed in the stem between ISK index and DON concentration $(P<$ $0.0001, R=0.44)$, ISK index and $3 \mathrm{ADON}$ concentration $(P<0.0001$, $R=0.34)$, ISK index and 15ADON concentration $(P<0.0001, R=$ 0.32) (Table 6), DISK index and DON concentration $(P<0.0001$, $R=0.45)$, DISK index and 3ADON concentration $(P<0.0001, R=$ $0.36)$, and DISK index and 15ADON concentration $(P<0.0001$, $R=0.31$ ) in the stem (Table 7). When separated by resistance class, FHB index was positively, significantly correlated to $15 \mathrm{ADON}$ concentration $(P=0.004, R=0.41)$ in the stem of the MS cultivars but no other correlations were significant (Table 5). Significant, positive

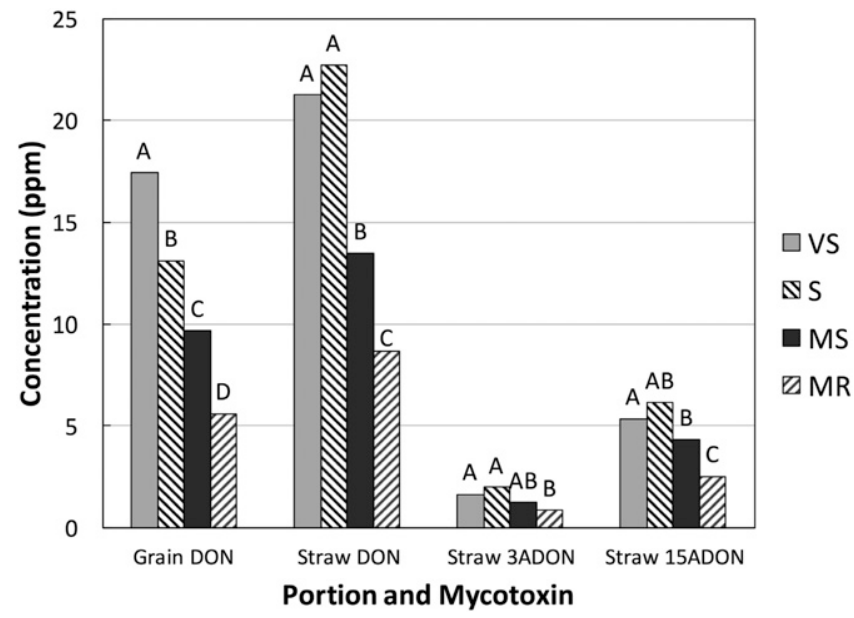

Fig. 1. Average mycotoxin concentrations in the stem and grain reported in parts per million (ppm) across all years by tissue. Values are back-transformed concentrations of each mycotoxin in the indicated tissue. Letters indicate significant differences between resistance classes for each mycotoxin using Tukey's W test with $\alpha=$ 0.05. Resistance classes were moderately resistant (MR), moderately susceptible (MS), susceptible (S), and very susceptible (VS). DON = deoxynivalenol, 3ADON = 3-acetyl-deoxynivalenol, and 15ADON = 15-acetyl-deoxynivalenol.

Table 3. Spearman correlation analysis was used to determine the correlation coefficients and significance of the correlations between the deoxynivaleno (DON) accumulation in the grain and the accumulation of DON, 3-acetyldeoxynivalenol (3ADON), and 15-acetyl-deoxynivalenol (15ADON) in wheat straw for each resistance class and overall

\begin{tabular}{llcrccc}
\hline & & \multicolumn{5}{c}{ Grain DONa } \\
\cline { 3 - 7 } Straw & Measured & VS & \multicolumn{1}{c}{ S } & MS & MR & Overall \\
\hline DON & $R$ & 0.005 & 0.03 & 0.03 & 0.45 & 0.33 \\
& $P$ value & 0.98 & 0.81 & 0.84 & 0.06 & $<0.0001$ \\
3ADON & $R$ & -0.004 & -0.09 & 0.18 & 0.13 & 0.30 \\
& $P$ value & 0.98 & 0.47 & 0.23 & 0.60 & $<0.0001$ \\
15ADON & $R$ & -0.20 & 0.08 & -0.10 & 0.28 & 0.16 \\
& $P$ value & 0.26 & 0.52 & 0.50 & 0.25 & 0.04 \\
\hline
\end{tabular}

${ }^{a}$ Resistance classes were moderately resistant (MR), moderately susceptible (MS), susceptible (S), and very susceptible (VS).

Table 2. Analysis of variance for Fusarium mycotoxins with reported degrees of freedom (df) and $P$ values for all main effects and the interaction for the mycotoxin concentrations reported in the wheat straw and grain and for all indices ${ }^{\mathrm{a}}$

\begin{tabular}{|c|c|c|c|c|c|c|c|c|c|c|}
\hline \multirow[b]{2}{*}{ Effects } & \multicolumn{2}{|c|}{ Grain } & \multicolumn{4}{|c|}{ Straw } & \multicolumn{4}{|c|}{ Indices } \\
\hline & df & DON & df & DON & 3ADON & 15ADON & df & FHB & ISK & DISK \\
\hline Class & 3 & 0.0001 & 3 & 0.003 & 0.03 & $<0.0001$ & 3 & $<0.0001$ & 0.006 & 0.004 \\
\hline Year & 2 & $\mathrm{NE}$ & 2 & 0.05 & 1.00 & 0.001 & 2 & 0.0002 & 0.41 & 0.52 \\
\hline Class $\times$ year & 6 & 0.64 & 6 & 1.00 & 1.00 & $\mathrm{NE}$ & 6 & NE & 0.33 & 0.39 \\
\hline Error & 150 & 0.09 & 149 & 0.23 & 0.12 & 0.19 & 150 & 266.16 & 67.42 & 38.21 \\
\hline
\end{tabular}

a DON = deoxynivalenol; 3ADON = 3-acetyl-deoxynivalenol; 15ADON = 15-acetyl-deoxynivalenol; FHB = Fusarium head blight; ISK = incidence, severity, and kernel damage index; DISK $=$ DON, incidence, severity, and kernel damage index; and NE $=$ not estimable . 
correlations were also observed in the stem of the VS cultivars between ISK index and DON concentration $(P=0.02, R=0.40)$, ISK index and 15ADON concentration $(P=0.01, R=0.43)$ (Table 6), DISK index and DON concentration $(P=0.03, R=$ $0.38)$, and DISK index and 15ADON concentration $(P=0.04, R=$ 0.36) (Table 7).

\section{Discussion}

Based on the results of this study, it was determined that resistance class is significantly associated with the concentration of Fusarium mycotoxins present in wheat stems. Reductions in DON concentration have generally been reported in cultivars with type II resistance,

Table 4. Spearman correlation analysis was used to determine the correlation coefficients and significance of the correlations between the accumulation of Fusarium mycotoxins in the stem for each resistance class and overalla

\begin{tabular}{llccccc}
\hline & & \multicolumn{5}{c}{ Stem DON $^{\text {DO }}$} \\
\cline { 3 - 7 } Stem & Measured & VS & $\mathbf{S}$ & MS & MR & Overall \\
\hline 3ADON & $R$ & 0.65 & 0.49 & 0.73 & 0.62 & 0.71 \\
& $P$ value & $<0.0001$ & $<0.0001$ & $<0.0001$ & 0.006 & $<0.0001$ \\
15ADON & $R$ & 0.82 & 0.83 & 0.75 & 0.89 & 0.81 \\
& $P$ value & $<0.0001$ & $<0.0001$ & $<0.0001$ & $<0.0001$ & $<0.0001$ \\
\hline
\end{tabular}

${ }^{\mathrm{a}} \mathrm{DON}=$ deoxynivalenol, $3 \mathrm{ADON}=3$-acetyl-deoxynivalenol, and $15 \mathrm{ADON}=$ 15-acetyl-deoxynivalenol.

${ }^{b}$ Resistance classes were moderately resistant (MR), moderately susceptible (MS), susceptible (S), and very susceptible (VS).

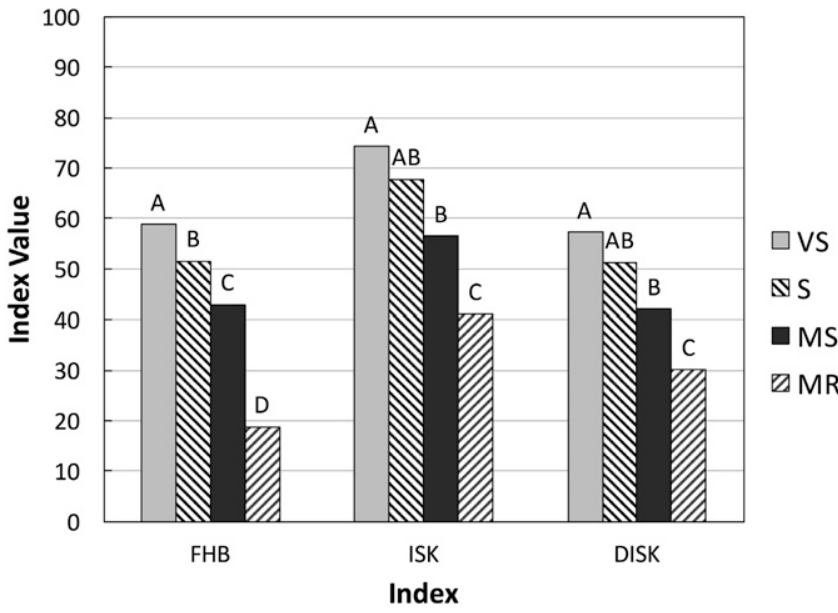

Fig. 2. Average index values by resistance class across all years. Letters indicate significant differences between resistance classes for each index using Tukey's W test with $\alpha=0.05$. Resistance classes were moderately resistant (MR), moderately susceptible (MS), susceptible (S), and very susceptible (VS). FHB = Fusarium head blight; ISK = incidence, severity, and kernel damage index; and DISK = deoxynivalenol, incidence, severity, and kernel damage index.

Table 5. Spearman correlation analysis was used to determine the correlation coefficients and significance of the correlations between Fusarium head blight (FHB) index and stem mycotoxin accumulation in each resistance class and overall

\begin{tabular}{llrrccc}
\hline & & \multicolumn{5}{c}{ FHB index $^{\mathbf{a}}$} \\
\cline { 3 - 7 } Stem $^{\mathbf{b}}$ & Measured & \multicolumn{1}{c}{ VS } & \multicolumn{1}{c}{ S } & MS & MR & Overall \\
\hline DON & $R$ & 0.17 & -0.04 & 0.24 & 0.18 & 0.37 \\
& $P$ value & 0.35 & 0.77 & 0.10 & 0.48 & $<0.0001$ \\
3ADON & $R$ & -0.23 & -0.03 & 0.13 & 0.07 & 0.24 \\
& $P$ value & 0.20 & 0.81 & 0.39 & 0.78 & 0.002 \\
15ADON & $R$ & 0.27 & -0.01 & 0.41 & 0.09 & 0.33 \\
& $P$ value & 0.13 & 0.92 & 0.004 & 0.71 & $<0.0001$ \\
& &
\end{tabular}

${ }^{a}$ Resistance classes were moderately resistant (MR), moderately susceptible (MS), susceptible (S), and very susceptible (VS).

${ }^{\mathrm{b}} \mathrm{DON}=$ deoxynivalenol, $3 \mathrm{ADON}=3$-acetyl-deoxynivalenol, and $15 \mathrm{ADON}=$ 15-acetyl-deoxynivalenol. indicating that cultivars with moderate resistance often result in lower mycotoxin concentrations in the grain (Jiang et al. 2007; Miller et al. 1985; Snijders and Krechting 1992). Significantly lower index ratings for all indices and significant DON reductions in the grain and stems of the MR cultivars observed in this study reinforce previous findings. The mechanism for these reductions may be related to the ability of a cultivar to detoxify DON into DON-3-glucoside within the host (Lemmens et al. 2005), a form of DON with reduced protein inhibition. Based on this biochemical process, the advancement of breeding programs that develop genotypes that reduce DON concentration in the grain may also result in decreases in DON concentrations in the stem through detoxification.

The colonization of tissue of cereal crops by Fusarium spp. relies primarily on mycotoxin production, especially DON, after initial infection (Mudge et al. 2006). By preventing the colonization of plant tissue by the fungus through the use of type II resistance, the plant, in theory, can effectively reduce mycotoxin concentrations. In this study, reductions in the concentration of DON were observed in both the grain and stem of MR cultivars. However, significant reductions in mycotoxin concentrations were not observed in the stem of the VS and $S$ cultivars. These resistance classes may not be able to sufficiently reduce mycotoxin concentration in the stem due to their inability to prevent the spread of Fusarium infection or to detoxify DON. Research by Li et al. (2010) and Ji et al. (2015) has suggested that some cultivars that confer resistance to FHB and DON concentration in grain may not show reductions or resistance to mycotoxin accumulation in the stem.

With the prevalence of the 15ADON chemotype in the Midwest (Abbas et al. 1986; Abramson et al. 2001; Miller and Greenhalgh 1991), the high levels of 15 ADON found in conjunction with

Table 6. Spearman correlation analysis was used to determine the correlation coefficients and significance of the correlations between incidence, severity, and kernel rating (ISK) index and stem mycotoxin accumulation in each resistance class and overall

\begin{tabular}{lllrrrc}
\hline & & \multicolumn{5}{c}{ ISK index $^{\mathbf{a}}$} \\
\cline { 3 - 7 } Stem $^{\mathbf{b}}$ & Measured & VS & \multicolumn{1}{c}{ S } & MS & \multicolumn{1}{c}{ MR } & Overall \\
\hline DON & $R$ & 0.40 & 0.04 & 0.14 & -0.22 & 0.44 \\
& $P$ value & 0.02 & 0.73 & 0.36 & 0.37 & $<0.0001$ \\
3 ADON & $R$ & 0.01 & -0.12 & 0.10 & -0.10 & 0.34 \\
& $P$ value & 0.97 & 0.32 & 0.49 & 0.70 & $<0.0001$ \\
15ADON & $R$ & 0.43 & 0.11 & 0.20 & -0.28 & 0.32 \\
& $P$ value & 0.01 & 0.39 & 0.17 & 0.26 & $<0.0001$ \\
& & &
\end{tabular}

${ }^{\mathrm{a}}$ ISK index $=(0.3) \times$ Incidence $+(0.3) \times$ Severity $+(0.4) \times$ Fusarium damaged kernel rating. Resistance classes were moderately resistant (MR), moderately susceptible (MS), susceptible (S), and very susceptible (VS).

${ }^{\mathrm{b}} \mathrm{DON}=$ deoxynivalenol, $3 \mathrm{ADON}=3$-acetyl-deoxynivalenol, and 15ADON = 15-acetyl-deoxynivalenol.

Table 7. Spearman correlation analysis was used to determine the correlation coefficients and significance of the correlations between deoxynivalenol (DON), incidence, severity, and kernel rating (DISK) index and stem mycotoxin accumulation in each resistance class and overall

\begin{tabular}{llrrrrc}
\hline & & \multicolumn{5}{c}{ DISK index $^{\mathbf{a}}$} \\
\cline { 3 - 7 } Stem $^{\mathbf{b}}$ & Measured & VS & \multicolumn{1}{c}{ S } & MS & MR & Overall \\
\hline DON & $R$ & 0.38 & 0.04 & 0.11 & -0.21 & 0.45 \\
& $P$ value & 0.03 & 0.73 & 0.45 & 0.40 & $<0.0001$ \\
3ADON & $R$ & 0.02 & -0.14 & 0.13 & -0.07 & 0.36 \\
& $P$ value & 0.91 & 0.26 & 0.38 & 0.77 & $<0.0001$ \\
15ADON & $R$ & 0.36 & 0.12 & 0.14 & -0.27 & 0.31 \\
& $P$ value & 0.04 & 0.33 & 0.36 & 0.28 & $<0.0001$ \\
\hline
\end{tabular}

a DISK index $=(0.2) \times$ Incidence $+(0.2) \times$ Severity $+(0.3) \times$ Fusarium damaged kernel rating $+(0.3) \times$ grain DON . Resistance classes were moderately resistant (MR), moderately susceptible (MS), susceptible (S), and very susceptible (VS).

b 3 ADON $=3$-acetyl-deoxynivalenol and 15ADON $=15$-acetyldeoxynivalenol. 
DON in this study were expected. The acetylated derivatives of DON are all derived from the same biochemical pathway that is used to create DON, making the significant, positive correlation observed among all three mycotoxins in the stem expected. Fewer significant differences in $3 \mathrm{ADON}$ levels among resistance classes were found in this study, likely because $3 \mathrm{ADON}$ concentrations were much lower than the concentrations of either DON or $15 \mathrm{ADON}$ in each year. Research by Alexander et al. (2011) indicated that $3 \mathrm{ADON}$ production may be related to interactions among 15ADON-producing isolates and can be present in low amounts as byproducts of the trichothecene biochemical pathways. The detection of $3 \mathrm{ADON}$ in this study may also be of concern, especially with the establishment of 3ADON chemotypes in the upper Midwest and across the Canadian prairies (Puri and Zhong 2010; Ward et al. 2008). However, with ISK and DISK index values remaining consistent across years and the significant correlation between $3 \mathrm{ADON}$ and $15 \mathrm{ADON}$ in this study, the low levels of 3-ADON may not be related to the presence of a new chemotype of $F$. graminearum but, rather, may be the result of interactions among established isolates and fluctuations in disease from year to year.

In this study, FHB index was a poor indicator of the relationship between FHB and the concentration of mycotoxins in the stem, with a large amount of variability observed beyond the effects of year and resistance class by year. What exactly is contributing to this wide variability is unknown. It may be attributed to the factors present in the other indices such as the utilization of percent FDK and DON concentration. FDK and DON concentration in the ISK and DISK indices significantly improve the models and removes a large amount of error that was present in the FHB index. The concentration of DON in wheat grains and rachis tissue has been found to be positively correlated to the amount of fungal biomass present (Miller et al. 1985), also indicating that FDK may help to predict DON concentration in the grain. This is especially important in situations where DON testing is difficult or not feasible.

ISK index is the focus of the University of Illinois wheat-breeding program for the advancement of wheat lines resistant to $F$. graminearum colonization and spread in the head. A relationship between DON concentration in the grain and ISK was expected in this study. However, this relationship was very weak or nonexistent within each resistance class. The reason for this may be due to differences in cultivars from year to year. DISK was also tested to determine its ability to indicate the presence of Fusarium mycotoxins in the stem. Both the ISK and DISK indices were similar in the differences observed among resistance classes for mycotoxin concentration in the stem and in their index values, indicating that either index provides a comparable estimation of mycotoxin concentration in the stem. However, the DISK index is not practical for all wheat-breeding scenarios. This is especially true for the advancement of winter wheat cultivars due to the timing of fall planting and the limited ability to complete and utilize mycotoxin analyses prior to the next breeding cycle. The use of DISK would be more useful in spring wheat-breeding programs. The ISK index allows for the advancement of FHB resistance in a timely fashion for winter wheat cultivars.

Resistance class has long been established as the most effective means to prevent the spread of FHB and reduce the accumulation of Fusarium mycotoxins. This study supports the idea that MR cultivars offer significantly greater control of FHB and reduced mycotoxin concentration in the grain over other resistance classes. Studies have indicated that the environment, as related to disease pressure, plays a large role in the effectiveness and performance of a cultivar in its resistance to FHB (Fuentes et al. 2005; Paul et al. 2005). In this study, the performance of each resistance class remained consistent across years. With no significant contribution of year to DON concentration in the grain in this study, it can be determined that the resistance class affected the concentration of mycotoxins in the grain independent of the variability in the environment. However, with significant differences reported across years for mycotoxin concentrations in the stem, environment may play a role in the performance of a cultivar in its ability to prevent mycotoxins from accumulating in the stem.

Overall, resistance class had the largest impact on the concentration of Fusarium mycotoxins in wheat stems. Although indices are commonly used for the advancement of FHB resistance in grain production, they may not prove to be as useful for the development of cultivars resistant to mycotoxin accumulation in the stem. ISK and DISK may provide more comprehensive estimations of Fusarium mycotoxin concentrations in the stem resulting from FHB. Further research into the mechanisms for DON detoxification and how Fusarium colonization contributes to the concentration of DON is necessary to develop cultivars that are effectively resistant to mycotoxin accumulation in both the grain and the stem.

\section{Acknowledgments}

We thank Y. Dong and her lab for providing mycotoxin data on grain and stem samples; A. Krill and N. Smith for their assistance and expertise in the implementation and maintenance of the field trials; and numerous summer workers and lab members for their assistance in collecting and processing stem samples.

\section{Literature Cited}

Abbas, H. K., Mirocha, C. J., and Tuite, J. 1986. Natural occurrence of deoxynivalenol, 15-acetyl-deoxynivalenol, and zearalenone in refusal factor corn stored since 1972. Appl. Environ. Microbiol. 51:841-843.

Abramson, D., Clear, R. M., Gaba, D., Smith, D. M., Patrick, S. K., and Saydak, D. 2001. Trichothecene and moniliformin production by Fusarium species from western Canadian wheat. J. Food Prot. 64:1220-1225.

Alexander, N. J., McCormick, S. P., Waalwijk, C., van der Lee, T., and Proctor, R. H. 2011. The genetic basis for 3-ADON and 15-ADON trichothecene chemotypes in Fusarium. Fungal Genet. Biol. 48:485-495.

Blandino, M., Haidukowski, M., Pascale, M., Plizzari, L., Scudellari, D., and Reyneri, A. 2012. Integrated strategies for the control of Fusarium head blight and deoxynivalenol contamination in winter wheat. Field Crops Res. 133:139-149.

Buerstmayr, H., Ban, T., and Anderson, J. A. 2009. QTL mapping and markerassisted selection for Fusarium head blight resistance in wheat: A review. Plant Breed. 128:1-26.

Buerstmayr, H., Lemmens, M., Hartl, L., Doldi, L., Steiner, B., Stierschneider, M., and Ruckenbauer, P. 2002. Molecular mapping of QTLs for Fusarium head blight resistance in spring wheat. I. Resistance to fungal spread (Type II resistance). Theor. Appl. Genet. 104:84-91.

Buerstmayr, M., and Buerstmayr, H. 2015. Comparative mapping of quantitative trait loci for Fusarium head blight resistance and anther retention in the winter wheat population Capo $\times$ Arina. Theor. Appl. Genet. 128:1519-1530.

Engle, J. S., De Wolf, E. D., and Lipps, P. E. 2000. A visual scale for estimating damage to soft red winter wheat kernels by Fusarium head blight. Pages 141-142 in: Proc. Natl. Fusarium Head Blight Forum. K. Y. Erlander, R. W. Ward, S. M. Canty, J. Lewis, and L. Siler, eds. Michigan State University, East Lansing.

Fuentes, R. G., Mickelson, H. R., Busch, R. H., Dill-Macky, R., Evans, C. K., Thompson, W. G., Wiersma, J. V., Xie, W., Dong, Y., and Anderson, J. A. 2005. Resource allocation and cultivar stability in breeding for Fusarium head blight resistance in spring wheat. Crop Sci. 45:1965-1972.

Gilbert, J., and Woods, S. M. 2006. Strategies and Considerations for Multilocation FHB Screening Nurseries. Pages 93-102 in: The Global Fusarium Initiative for International Collaboration: A Strategic Planning Workshop, CIMMYT, El Batan, Mexico. T. Ban, J. M. Lewis, and E. E. Phipps, eds. CIMMYT, Mexico, D.F.

Häggblom, P., and Nordkvist, E. 2015. Deoxynivalenol, zearalenone, and Fusarium graminearum contamination of cereal straw; field distribution; and sampling of big bales. Mycotoxin Res. 31:101-107.

Ji, F., Wu, J., Zhao, H., Xu, J., and Shi, J. 2015. Relationship of deoxynivalenol content in grain, chaff, and straw with Fusarium head blight severity in whea varieties with various levels of resistance. Toxins (Basel) 7:728-742.

Jiang, G. L., Dong, Y., Shi, J., and Ward, R. W. 2007. QTL analysis of resistance to Fusarium head blight in the novel wheat germplasm CJ 9306. II. Resistance to deoxynivalenol accumulation and grain yield loss. Theor. Appl. Genet. 115: 1043-1052.

Kolb, F. L., and Boze, L. K. 2003. An alternative to the FHB index: Incidence, severity, kernel rating (ISK) index. Page 259 in: Proc. 2003 Natl. Fusarium Head Blight Forum, East Lansing, MI. S. Canty, A. Clark, J. Mundell, E. Walton, D. Ellis, and D. Van Sanford, eds. University of Kentucky, Erlanger.

Lemmens, M., Scholz, U., Berthiller, F., Dall'Asta, C., Koutnik, A., Schuhmacher, R., Adam, G., Buerstmayr, H., Mesterházy, Á., Krska, R., and Ruckenbauer, P. 2005. The ability to detoxify the mycotoxin deoxynivalenol colocalizes with a major quantitative trait locus for Fusarium head blight resistance in wheat Mol. Plant-Microbe Interact. 18:1318-1324.

Li, H. B., Xie, G. Q., Ma, J., Liu, G. R., Wen, S. M., Ban, T., Chakraborty, S., and Liu, C. J. 2010. Genetic relationships between resistances to Fusarium head blight and crown rot in bread wheat (Triticum aestivum L.). Theor. Appl. Genet. 121:941-950.

Marasas, W. F. O., van Rensburg, S. J., and Mirocha, C. J. 1979. Incidence of Fusarium species and the mycotoxins, deoxynivalenol and zearalenone, in corn produced in esophageal cancer areas in Transkei. J. Agric. Food Chem. 27:1108-1112. 
Miller, J. D., and Greenhalgh, R. 1991. Trichothecene chemotypes of three Fusarium species. Mycologia 83:121-130.

Miller, J. D., Young, J. C., and Sampson, D. R. 1985. Deoxynivalenol and Fusarium head blight resistance in spring cereals. Phytopathol. Z. 113:359-367.

Mirocha, C. J., Christensen, C. M., and Nelson, G. H. 1967. Estrogenic metabolite produced by Fusarium graminearum in stored corn. Appl. Microbiol. 15: 497-503.

Mirocha, C. J., Pathre, S. V., Schauerhamer, B., and Christensen, C. M. 1976. Natural occurrence of Fusarium toxins in feedstuff. Appl. Environ. Microbiol. 32:553-556.

Mudge, A. M., Dill-Macky, R., Dong, Y., Gardiner, D. M., White, R. G., and Manners, J. M. 2006. A role for the mycotoxin deoxynivalenol in stem colonisation during crown rot disease of wheat caused by Fusarium graminearum and Fusarium pseudograminearum. Physiol. Mol. Plant Pathol. 69:73-85.

Nganje, W. E., Bangsund, D. A., Larry Leistritz, F., Wilson, W. W., and Tiapo, N. M. 2004. Regional economic impacts of Fusarium head blight in wheat and barley. Rev. Agric. Econ. 26:332-347.

Nielsen, E. K., and Ingvartsen, K. L. 2000. Effects of cereal disintegration method, feeding method and straw as bedding on stomach characteristics including ulcers and performance in growing pigs. Acta Agric. Scand. Sect. Anim. Sci. 50:30-38.

Nordkvist, E., and Häggblom, P. 2014. Fusarium mycotoxin contamination of cereals and bedding straw at Swedish pig farms. Anim. Feed Sci. Technol. 198:231-237.

Paul, P. A., Lipps, P. E., Hershman, D. E., McMullen, M. P., Draper, M. A., and Madden, L. V. 2008. Efficacy of triazole-based fungicides for Fusarium head blight and deoxynivalenol control in wheat: A multivariate meta-analysis. Phytopathology 98:999-1011.

Paul, P. A., Lipps, P. E., and Madden, L. V. 2005. Relationship between visual estimates of Fusarium head blight intensity and deoxynivalenol accumulation in harvested wheat grain: A meta-analysis. Phytopathology 95:1225-1236.

Paul, P. A., McMullen, M. P., Hershman, D. E., and Madden, L. V. 2010. Metaanalysis of the effects of triazole-based fungicides on wheat yield and test weight as influenced by Fusarium head blight intensity. Phytopathology 100: 160-171.

Prat, N., Buerstmayr, M., Steiner, B., Robert, O., and Buerstmayr, H. 2014. Current knowledge on resistance to Fusarium head blight in tetraploid wheat. Mol. Breed. 34:1689-1699.

Puri, K. D., and Zhong, S. 2010. The 3ADON population of Fusarium graminearum found in North Dakota is more aggressive and produces a higher level of DON than the prevalent $15 \mathrm{ADON}$ population in spring wheat. Phytopathology 100:1007-1014.

Rohweder, D., Kersten, S., Valenta, H., Sondermann, S., Schollenberger, M., Drochner, W., and Dänicke, S. 2013. Bioavailability of the Fusarium toxin deoxynivalenol (DON) from wheat straw and chaff in pigs. Arch. Anim. Nutr. 67:37-47.

Rohweder, D., Valenta, H., Sondermann, S., Schollenberger, M., Drochner, W., Pahlow, G., Döll, S., and Dänicke, S. 2011. Effect of different storage conditions on the mycotoxin contamination of Fusarium culmorum -infected and non-infected wheat straw. Mycotoxin Res. 27:145-153.

Schroeder, H. W., and Christensen, J. J. 1963. Factors affecting resistance of wheat to scab caused by Gibberella zeae. Phytopathology 53:831-838.

Shaner, G. 2003. Epidemiology of Fusarium head blight of small grain cereals in North America. Pages 84-119 in: Fusarium Head Blight of Wheat and Barley. K. J. Leonard and W. R. Bushnell, eds. American Phytopathological Society, St. Paul, MN.

Snijders, C. H. A. 1990. Genetic variation for resistance to Fusarium head blight in bread wheat. Euphytica 50:171-179.

Snijders, C. H. A., and Krechting, C. F. 1992. Inhibition of deoxynivalenol translocation and fungal colonization in Fusarium head blight resistant wheat Can. J. Bot. 70:1570-1576.

Stack, R., and McMullen, M. 2011. A Visual Rating Scale to Estimate Severity of Fusarium Head Blight in Wheat. PP-1095. North Dakota State University, Fargo.

Tanaka, H., Takino, M., Sugita-Konishi, Y., and Tanaka, T. 2006. Development of a liquid chromatography/time-of-flight mass spectrometric method for the simultaneous determination of trichothecenes, zearalenone and aflatoxins in foodstuffs. Rapid Commun. Mass Spectrom. 20:1422-1428.

USDA FDA. 2010. Advisory Levels for Deoxynivalenol (DON) in Finished Wheat Products for Human Consumption and Grains and Grain By-products Used for Animal Feed. United States Department of Health and Human Services Food and Drug Administration, Rockville, MD.

van Barneveld, R., Edwards, T., and Choct, M. 2005. Accurate assessment of diet intake and composition in various pig housing systems. APL Project 1754. Australian Pork Ltd., Kingston, ACT, Australia.

Vesonder, R. F., and Hesseltine, C. W. 1981. Vomitoxin: Natural occurrence on cereal grains and significance as a refusal factor and emetic factor to swine. Process Biochem. 16:12-15.

Veum, T. L., Crenshaw, J. D., Crenshaw, T. D., Cromwell, G. L., Easter, R. A., Ewan, R. C., Nelssen, J. L., Miller, E. R., Pettigrew, J. E., and Ellersieck, M. R. 2009. The addition of ground wheat straw as a fiber source in the gestation diet of sows and the effect on sow and litter performance for three successive parities. J. Anim. Sci. 87:1003-1012.

Ward, T. J., Clear, R. M., Rooney, A. P., O’Donnell, K., Gaba, D., Patrick, S., Starkey, D. E., Gilbert, J., Geiser, D. M., and Nowicki, T. W. 2008. An adaptive evolutionary shift in Fusarium head blight pathogen populations is driving the rapid spread of more toxigenic Fusarium graminearum in North America. Fungal Genet. Biol. 45:473-484. 